\title{
The Dynamics of Metaphor: Foregrounding and Activating Metaphoricity in Conversational Interaction
}

The idea of a dynamics of metaphor emerged with advances in psycholinguistics and applied linguistics research. Today, different fields understand how a metaphor might be dynamic in different ways. For psychologists, dynamics mostly refers to retrieving or comprehending metaphorical concepts as an online process of an individual; for applied linguists on the other hand, dynamics addresses the forms of metaphor in use extending over a discourse or a conversational interaction; and for neurologists, dynamics refers to the dynamic activation of neural webs. In this article we will attempt to bring together the psychological and linguistic perspective. We propose that an analysis of the embodied dynamics of metaphor shows how metaphoricity dynamically unfolds over time in a conversational interaction (this is a pattem which extends linearly in time) and how at the same time it may be graded, i.e. showing different degrees of metaphor activation (these are simultaneous patterns realized at one given moment in time). We propose to merge a cognitive linguistic take on metaphor with a sequential analytical approach to conversational interaction. In this dynamic view (Müller 2008a), metaphor activation is both an interactive and individual process. We will suggest that metaphor activation is observable as a multimodal salience structure, which consists of verbal, gestural and verbo-gestural metaphors that are foregrounded to various degrees. Degrees can be empirically determined through a descriptive analysis of foregrounding strategies employed by participants in a conversational interaction. We will furthermore propose that, in cognitive terms, this dynamic foregrounding of metaphoricity over the course of a conversation goes along with a constantly moving focus of attention (cf. also Chafe 1994, 1996). Foregtounding of metaphoricity also implies an embodied experience of metaphor and thus activation comes with an affective or experiential quality.

The core assumption is: if metaphoricity is being foregrounded it is also activated - ideally for both the speaker and the listener. We illustrate this proposal with microanalyses of naturalistic conversations and we present a descriptive method for analyzing metaphor foregrounding processes as interactive, cognitive, and ultimately emotional processes.

CORRESPONDENCE: Comelia Müller. Europa-Universität Viadrina, Frankturt (Oder). Germany. EMAIL: Sekretariat-CMueller@euv-trankfurt-o.de | Susanne Tag. Freie Universităt Berlin, Germany. EMAlL: sutag@zedat.fu-berlin.de 
Over the past decade, metaphor scholars have paid increasing attention to the dynamic nature of metaphors. This is a significant move away from traditional and contemporary approaches to metapho: whose primary focus is on metaphors as lexical or conceptual units. When, for instance methods of metaphor identification are developed, such as the MIP and the MIPVU (Pragglejaz Group 2007; Steen et al. 2010), they apply a word-by-word procedure and therefore start from the assumption that each word can potentially be metaphoric. They do not account for a dynamic gradability of metaphoricity or for the dynamic development of metaphors over time in a conversation. Cameron's idea of systematic metaphors, however, aims at a discourse level of metaphor, which presupposes a dynamic unfolding and an interactive process of - what we would term - activating metaphoricity over the time of a given discourse (Cameron 1999, 2007; Cameron et al. 2009; Gibbs \& Cameron 2008; Larsen-Freeman \& Cameron 2008).

The 'static' perspective on metaphor characterized many earlier and contemporary metaphor theories. Metaphors tended to be regarded as either 'dead' or 'alive', either vital or non-vital, either poetic or ordinary (cf. Müller 2008a for a detailed discussion of this). Prototypically, metaphoricity was regarded as a property of a lexical item or of a structure of thought. Although since Aristotle metaphor was theoretically conceived of as a matter of language in use, it was not studied as such. This held even for pragmatic approaches to metaphor, which, rather than studying metaphoric expressions as they are used in actual real life situations, relied on decontextualized and mostly invented examples, such as Sally is a block of ice (Searle 1993).

The rising interest into the dynamic dimensions of metaphor is an almost natural consequence of a shift of metaphor research towards studying metaphors in their actual contexts of use. To some degree, it is also a consequence of the availability of recording techniques that allowed storing and repeated minute analyses of spoken language data: "Taking metaphor out of our heads and putting it into the cultural world" as Ray Gibbs put it in the late nineties (Gibbs 1999) is at the heart of an applied approach to metaphor studies. Since then a series of conferences and workshops has been devoted to applied metaphor research which led to the foundation of an international association for Researching and Applying Metaphor (RaAM), the launch of an international journal Metaphor in the Social World (ed. by Lynne Cameron and Graham Low) and a book series Metaphor in Language, Cognition, Communication (ed. by Gerard Steen), - to mention only some of the most significant institutional testimonies of this young line of research. ${ }^{1}$

With their edited volume on the topic, Lynne Cameron and Graham Low set the stage for an applied linguistic approach to metaphor analysis (Cameron \& Low 1999). In her introductory chapter, Cameron puts forward two meta-

1 See the homepage of the Association for Researching and Applying metaphor, RaAM (<www.raam.org.uk>, last access on 1.11.2010). 
theoretical arguments, both of which are at the heart of applied metaphor research and regard dynamic perspectives on metaphor. In her introduction to the book, she proposes a dynamic systems approach to metaphor in discourse and by extending an argument made by Herb Clark (1996); she argues that in order to arrive at a full picture on metaphor in language in use we must dynamically integrate a cognitive and a social perspective:

As Clark (1996) points out, if we take a purely cognitive approach or a purely socio-cultural approach to language use and, by extension, to an aspect of language use such as metaphor, we do not get pictures that are differently but equally valid; rather, we get partial and inaccurate pictures, since it is precisely the interaction between the cognitive and social in language use that produces the language and behavior that we observe and research. (Cameron 1999: 4)

Theories and methodologies of metaphor should account for the intricate and dynamic interplay of cognitive and interactive factors when studying metaphors in language use. Cameron's dynamic systems approach regards language in use as "a complex dynamic system in which language resources - both forms of language and skills in using language - are employed in particular contexts to achieve interactional goals under particular processing demands." (Cameron 1999: 4). Note that Cameron frames the notion of language as a pool of resources that speaker's dispose of and that entails as much a system of language as the skills of using language. In fact, she regards language as a system, which emerges out of language use in interaction. Here is the full quote:

What we need is a view of language in use which prevents a one-sided or compartmentalized approach, by allowing the social and the cognitive to be integral parts of theory and analysis of data. Language in use in human interaction [...] can usefully be considered as a complex, dynamic system in which language resources - both forms of language and skills in using language - are employed in particular contexts to achieve interactional goals under particular processing demands. [...] Operationalising metaphor (or other concepts) for applied linguistic purposes requires that account is taken of resources (language and cognitive), interactional goals and processing demands at each point of theory development and research. (Cameron 1999: 4)

The dynamic view on metaphors in language use (see Müller 2003, 2007, 2008a) presented in this article is in line with Cameron's claim. It attempts to 'operationalize' her proposal to systematically integrating social and cognitive processes for the analysis of metaphor activation in conversational interaction (cf. also Müller 2008a,b). By analyzing the activities co-participants employ to foreground metaphoricity over the course of a conversation, our approach suggests a theoretical framework and a method to empirically reconstruct the intertwining of social, cognitive and affective processes. When metaphoricity is foregrounded, we assume that it is also activated - interactively, cognitively and affectively. When metaphoricity is also embodied gesturally, we assume that this 
implies a particular affective quality. ${ }^{2}$ Foregrounding of metaphoricity in a discourse is regarded as a process that unfolds in time and it is both simultaneously and linearly structured. From (social) foregrounding activities, we infer how metaphor is activated (interactionally, cognitively and affectively). We suggest that by analyzing the foregrounding activities of co-participants in a conversational interaction we can reconstruct how activation of metaphoricity unfolds over time in a discourse (this is the linear aspect of metaphor activation). And we may also establish to what degree it may be activated at successive moments in time (this is the simultaneous aspect of metaphor activation). We suggest that metaphor activation is a cognitive process in that it goes along with a moving focus of attention; we conceive of it also as affective process in that embodied metaphors imply a felt quality of meaning." "You must look at the felt qualities, images, feelings, and emotions that ground our more abstract structures of meaning." Johnson 2007: 17; cf. also Gibbs 2006; Sheets-Johnstone 1999), in other words, they come with an affective quality. The argument presented here follows a similar argumentative logic as Wallace Chafe's proposal to determine the flow of consciousness in discourse through the analysis of units of intonation (Chafe 1994, 1996). It is obvious that this type of argumentation is theoretically motivated. It is not aimed at being a falsifiable hypothesis, and it is clear that as such it doesn't meet the standards of experimental psychology.

However, there is some work in psychology that lends support to the idea of cognitive 'activation' of metaphoric meaning. One of the most prominent cases comes from Gibbs who has shown in various experimental studies that conceptual metaphors have priming effects on semantic processing (Gibbs 1999). Also Rachel Giora's graded salience hypothesis comes to mind as a way of approaching metaphor activation in terms of metaphor processing (in particular comprehension; Giora 1997, 2002, 2003). In many psycholinguistic experimental studies Giora addresses the long-debated issue of whether metaphoric meaning is processed as quickly as literal meaning (a question of dividing lines in psycholinguistic research of metaphor comprehension, cf. Gibbs 1994, 1998; Katz et. al 1998; Müller 1998a for an overview of this debate). Her studies suggest that it is the salience of a lexical item that determines the readiness of processing as opposed to a metaphoric versus literal meaning. Giora regards salience on the level of lexical entries in a mental lexicon and determines salience in terms of frequency, conventionality, familiarity, and prototypicality of lexical items. If a lexical item has a metaphoric and a non-metaphoric reading, then the more salient one (i.e. in terms of frequency, conventionality etc.) will be processed faster, no matter whether it is a metaphoric or a literal meaning of a word. However, both lines of study are concerned with comprehension. Our proposal of reconstructing activated

2 For a detailed exposition of this argument, see Kappelhoff \& Müller (in prep.).

3 I am grateful to Irene Mittelberg for directing my attention to Johnson's quote. 
metaphoricity through a metaphor foregrounding analysis concerns production and understanding - as far as they are displayed in an interaction.

In order to transform our assumption into a falsifiable hypothesis, an experimental setting would be needed that could, for instance, measure activation of metaphoricity in terms of activated neural webs (Barsalou 1999) and that could show different degrees of activated metaphoricity at a given moment in time (simultaneous perspective). It appears that Barsalou's theory of dynamic created ad hoc categories approaches a phenomenon of spontaneous meaning constitution that relates very much to the phenomenon of metaphor activation that we are interested in here: metaphors as a spontaneous product of an interactive process in which metaphoricity might be elaborated and unfolded over the course of a conversation.

A significant problem for experimental settings that test activation of metaphoricity is the temporal linear structure of metaphor activation - not to speak of the interactive dimension of it. Most established experimental settings for metaphor processing deal with single metaphoric units maximally at sentence level, not with metaphors shining up at different moments in a discourse. Imaging studies for instance and other tests of neural activity depend on a very strict type of stimulus, where a particular type of lexical item appears over a great amount of trials at precisely the same moment in time and within one type of syntactic structure. Psycholinguistic settings, such as priming studies for instance also measure on the level of singular items or sentence level at best. As far as I can see, there is no established experimental method to study the dynamic structures of metaphors in longer pieces of discourse, nor is there a way to study spontaneous metaphor production in its sequential and temporal structure. Corpus linguists study the distribution of lexical units or constructions over a large amount of corpora - but they too do not account for the temporal orchestration of metaphors as they unfold in real time in an ordinary conversation.

Here is where our theoretically motivated cognitive-linguistic and sequentialanalytical (or distributed cognition) approach comes in (cf. Goodwin 2003, 2007). It proposes a method to document activated metaphoricity as far as it is accountable for the attending participants in a conversation in terms of their foregrounding activities. We suggest that participants in a conversation coconstruct an interactively attainable salience structure, that they engage in a process of profiling metaphoric meaning by foregrounding it. What we as analysts can describe are these foregrounding activities and the profiling of metaphoricity in its linear and simultaneous temporal arrangements.

An example of a foregrounding activity would be the verbal unfolding of a metaphoric expression. And because the metaphor is being spontaneously elaborated, foregrounded, made prominent for an attending co-participant, we assume that it is cognitively activated at least for the speaker. Foregrounding is interactional in the sense of being addressed and approved by the coparticipant. Foregrounding may also entail embodied expressions of 
metaphoricity in the literal sense of the word, because speakers use gestures that exhibit the bodily dimension of a metaphor. Gestures that are created on the spot are in McNeill's terms "windows onto thought" (McNeill 1992). They are spontaneous (McNeill 1992) or singular (Müller 2010b) gestures and they relate to dynamic processes of utterance formation (McNeill 2005; Duncan et al. 2007). In concert with McNeill's argument, we suggest that spontaneously created gestures are directly related to 'activated' experiential source domains. They point towards activated metaphoricity, because apparently the source domain of the verbal metaphoric expression has triggered a pantomimic enactment - or vice versa. A bodily memory has triggered a respective verbal and bodily expression and with it a particular affective stance (cf. Fuchs 2006, 2008, 2009, Fuchs \& De Jaegher 2009; Fuchs \& Mundt, in prep.; Koch et al. in prep.). This analysis is coherent with current embodiment approaches, especially phenomenological ones, assuming that meaning constitution is always embodied and involves both cognitive and affective processes (Fuchs 2006, 2009; Fuchs \& De Jaegher 2009; Gallagher 2005; Johnson 2007; SheetsJohnstone 1999; see Gibbs 2006 for an overview). A metaphor expressed in word and in gesture is a prototypical form of embodied experience. Depending on a gesture's temporal placement in relation to the verbal metaphoric expression, it can be regarded as an embodiment of the verbally expressed meaning (if it is synchronized with or following a verbal metaphoric expression) or the verbal metaphor can be seen as an outcome of bodily thinking and feeling (in case the gesture precedes the verbal metaphoric expression). Some instances of these multimodally constructed utterances could also be explained by assuming an underlying conceptual metaphor, which is active and which triggers both verbal and gestural expressions? In fact, yes, if only we accept that conceptual metaphors include an active experiential domain, then both spontaneous gestures and verbal expressions indicate that this experiential domain is cognitively active at a given moment in time during a conversation. This argument would gain support from the experimental studies on cognitive processing of conceptual metaphors carried out by Gibbs, which show priming effects of contexts that trigger either metaphoric or non-metaphoric readings of a target sentence. (Gibbs 1999). In fact, eye tracking could be a future experimental path to follow for studying metaphor foregrounding activities as an unfolding temporal salience structure. If metaphoricity is interactively foregrounded gesturally, then these gestures should be more likely to receive listener's gaze than others.

Other recent studies show that affective judgments related to left (bad) and right (good) (in right handers) govern even non-linguistic decision tasks. (Casasanto 2009; Casasanto \& Jasmin 2010; Willems et al. 2009). In a series of experiments, Casasanto has shown that the left-right distinction is connected with positive (right) and bad (left) affective stances towards judging abstract graphical images. Most interestingly, he has found that this affective stance is positively correlated with left and right-handedness of the subjects. Thus left 
handers would take a more positive attitude towards the pictograms depicted on the left hand side and a more negative one towards the ones presented on the right hand side. For right-handers the same would apply. This indicates that activation of metaphors such as "left is bad" and "right is good" is not only a cognitive process in which metaphoric meaning is activated on the verbal level, but also an affective one. Casasanto's experiments also show that affect comes in through the embodied experience underlying the affective stance taken.

In the following sections, we will offer a summary of the dynamic view on metaphor activation, a systematics of the techniques that participants in a conversation use to foreground metaphoricity, a cognitive-linguistic and sequential-analytical (distributed cognition) method for analyzing metaphor foregrounding, a means for a graphical representation of the dynamic temporal arrangement of foregrounding activities (strategies) over the course of a conversation, and an analysis of two examples used to illustrate the sequential and cognitive-linguistic Metaphor Foregrounding Analysis (MFA). ${ }^{4}$

\title{
A dynamic view on metaphors in language use: sleeping and waking metaphors
}

\begin{abstract}
Furthermore, individual, partial representations of cultural conceptual metaphors may not always be pre-stored in their entirety in people's mental lexicons and encyclopedias. Parts of these conceptual metaphors may have to be (re) constructed in different ways on different occasions. At the same time, prestored conceptual metaphors may not always be activated when people immediately comprehend metaphorical language. (Gibbs \& Steen 1999: 3)
\end{abstract}

The dynamic view of sleeping and waking metaphors proposes a micro-analytic (qualitative) account of the psychological phenomenon which Gibbs and Steen have pointed out in their introduction to the collection of papers on Metaphors in Cognitive Linguistics: "Metaphors may not always be activated when people immediately comprehend [and produce, CM \& ST] metaphorical language." (Gibbs \& Steen 1999: 3).5 It considers metaphors in different types of discourses and situational contexts and addresses verbal, gestural, and verbogestural metaphors as well as verbo-pictorial and even audiovisual metaphors (Cienki 2008; Cienki \& Müller 2008a,b; Forceville 1998, 2002, 2004-2009, 2006; Forceville \& Urios-Aparisi 2009; Mittelberg 2008; Mittelberg \& Waugh 2009; Müller 2008a,b; Müller \& Cienki 2009). All these instances of metaphor usage share a fundamental property: they combine different modalities or modes of expression. We suggest that expressing metaphoric meaning in more than one modality indicates that a metaphor is waking. At least for spontaneous gestures

4 Both examples have been presented at various conferences and lectures over the past years and we are grateful for all the useful comments we received and which greatly improved our analyses and our argument. Earlier stages of a metaphor foregrounding analysis of example 1 have been published in Müller (2007, 2008a,b).

5 For a full exposition of the dynamic view advocated in this article, see Müller 2008a. 
that accompany speech, this argument is quite straightforward. For the other types of multimodal metaphor, the argument is less obvious, but we cannot go into detail about this now. For the type of multimodal metaphors regarded in this article it is important to ensure that there is no conventional link between a given word and a given gesture - the argument only holds if we assume that a gesture is a singular one, which has been spontaneously created (Müller 2010a, in prep.).

In fact, many studies have shown that even when people talk about similar domains of meaning, such as for instance about motion events (Allen et al 2007; Duncan 2002, 2006; Duncan et al. 2007; Kita \& Özyürek 2003; Müller 1998a; Özyürek 2002; Özyürek et al. 2005, 2008), or when they are prompted by a particular story and are asked to perform a gesture with the concluding sentence of the story (Ladewig et al. 2010) - the type of gestures they produce differs widely. These findings point towards a flexible relation between gestures and the speech with which they are coordinated.

Multimodal metaphors, i.e. metaphors that are produced in two modalities at the same time, such as in hand gestures and in words, are very likely to be ad hoc creations of a given speaker at a particular moment in time. And as such, they indicate activated metaphoricity. What happens is that the speaker draws upon the metaphoric source domain that is expressed by the verbal metaphoric expression to create a given gesture - or vice versa - an unwitting gesture might trigger a concurrent verbal metaphoric expression (Cienki \& Müller 2008b; Müller \& Cienki 2009). These multimodal metaphors foreground metaphoricity, they make it more salient, more prominent for an attending conversational partner. From an interactive point view, they show where the focus of attention sits and they draw the co-participants attention to these metaphoric expressions. ${ }^{6}$ The dynamic view considers those metaphors as waking metaphors. In another context the very same verbal metaphoric expression might be used too, but the metaphoric content neither shows up in an accompanying gesture nor is highlighted otherwise (for instance by a metacomment such as 'literally speaking' or by verbal elaborations (cf. Kyratzis 2003; Stibbe 1996; Müller 2008a for an overview). In those instances of language use metaphors are considered as sleeping. ${ }^{7}$ The metaphoricity is in the background and only minimally activated, if at all. It is evident that this argument only holds for transparent metaphors. Opaque metaphors in a given language cannot be activated in a given discourse.

Metaphoricity of a sleeping metaphor may very well become an anchor point for further elaborations. As the discourse unfolds, we can make these specific temporally orchestrated metaphor profilings visible through the metaphor foregrounding analysis that we propose in this article. Of course they

6 For an interactive take on attention and gestures, see Streeck 2009: 85-118. For a cognitivesemiotic perspective on attention, see Oakley 2008.

7 For a detailed discussion of the different traditions in categorizing metaphors as dead, dormant, active, vital, historical, entrenched, alive, see Müller (2008a: 178-209). 
can also turn into a point of anchorage for topic-comment structures in terms of what McNeill has termed early on "communicative dynamism" of the unfolding discourse (McNeill 1992, 2005) and they can be treated as interactively relevant 'objects' (Alibali \& Kita 2010; Gulberg \& Kita 2009; Streeck 1988, 1993, 2009).

The dynamic view on sleeping and waking metaphors proposes that metaphoricity is a property, which can be dynamically activated, where activation is an achievement of co-participants in a conversational interaction and hence depends on a particular context of use. Activation is considered a specific kind of ad hoc creation of meaning, which is made visible or which materializes in a dynamic foregrounding pattern of multimodal utterances. As such the proposal is in line with Barsalou's neurological theory of dynamic ad hoc created categories (Barsalou 1999) and with distributed cognition approaches in anthropology (Goodwin 2000, 2003, 2007; Streeck 1996; Streeck \& Le Baron 2000; Streeck \& Kallmeyer 2001). The dynamic view presented here assumes that transparent metaphors have a potential for metaphor activation and that they may range from sleeping to waking depending on their specific context of use. In sleeping ones metaphoricity is minimally activated, while in waking ones it is highly activated. Metaphoricity is regarded as a property of metaphors in language in use, and depending on its context of use it may be more or less activated. Degrees of activation are reconstructable through an account of foregrounding activities and strategies employed by participants in a conversation.

Activating metaphoricity manifests itself as a dynamic and temporally orchestrated profiling of multimodal utterances. It can be documented and reconstructed in terms of foregrounding activities and can be made visible as dynamically emerging patterns of foregrounding metaphoricity.

Based on the analysis of these foregrounding patterns, we assume that what has been foregrounded by a given speaker is also in the foreground of his or her cognitive processing, i.e. in the focus of his or her attentional scope. In short: what is interactively foregrounded is where the focus of attention sits, it is also cognitively active. And if a co-participant actively shares it, then this holds also for him or her. Metaphor activation regarded in this way follows an interactively negotiated flow of attention; it has an interactive as much as a cognitive and an affective side. The affective quality of activation comes in with the 'felt' experiences. It is an achievement of participants' conversational activities in the course of an interaction - and these activities are what can empirically be grasped as foregrounding strategies.

Foregrounding of metaphoricity regards two temporal dimensions (at least): a simultaneous one and a linear one - and so does activation of metaphoricity. Conceived of in this way metaphors are gradable, they can be more or less activated and they can become more and more activated as the conversation moves on. Gradability of metaphors ranges from sleeping to waking, depending on its context of use. 
How we can document foregrounding patterns over the course of a discourse, what foregrounding strategies we refer to, and more generally how we connect foregrounding with activation of metaphoricity in a cognitive-linguistic and sequential-analytical micro-analysis will be presented in the following section.

\section{Foregrounding and activation of metaphoricity}

We propose, that metaphor activation is empirically accountable as an interactively achieved profiling of multimodal utterances. From these profiling activities we not only infer activated metaphoricity (interactively, cognitively, affectively), but also we regard it as the interactive 'public' part of metaphor activation itself. The basic assumptions here are as follows:

$\Rightarrow$ What is interactively foregrounded is also cognitively and affectively activated.

$\Rightarrow$ The more instantiations of an experiential source domain, the more it is foregrounded and the higher the degree of activated metaphoricity is achieved.

$\Rightarrow$ The more cues that point towards metaphoric expressions, the more the expression is foregrounded and the higher the degree of activation.

We suggest that this interactively achieved profiling is empirically reconstructable in terms of particular foregrounding strategies.

1. Expressing metaphoricity in more than one modality foregrounds metaphoricity: This foregrounding strategy follows an Iconicity Principle.

2. By using salience markers, a verbal, gestural or verbo-gestural metaphor is additionally foregrounded. These salience markers follow Interactive, Semantic and Syntactic Principles.

\section{Expressing metaphoricity in more than one modality foregrounds metaphoricity:} The Iconicity Principle

When speakers employ more modalities at the same time or in very close temporal proximity to express metaphoric meaning, they mark it as prominent information (this is an interactive and cognitive dimension). On the other hand, when metaphors appear in gesture, we know the experiential source domain is embodied, it is experientially present and as such it also carries affective qualities. Using more than one modality to express a metaphor foregrounds metaphoricity in the ongoing utterance and it follows the iconicity principle of: More material indicates mone meaning. Transferred to metaphor this amounts to: More metaphorical material foregrounds metaphoric meaning. The Iconicity Principle is an important principle for motivated linguistic structures such as for instance in plural marking. Here reduplication of affixes marks more referents. This means that in the case of plural the Iconicity Principle is a quantity marker, while in 
the case of multimodal metaphors it foregrounds metaphorical meaning. For our documentation of the salience structures of multimodal utterances we have developed icons that depict different forms of realizing the iconicity principle in a Metaphor Foregrounding Analysis.

\begin{tabular}{|l|l}
\hline VME - & verbal metaphoric expression \\
\hline GME & gestural metaphoric expression - hand gesture \\
\hline GME 8 & gestural metaphoric expression - head gesture
\end{tabular}

Figure 1. Different forms of metaphoric expressions realizing the Iconic Principle.

\section{Salience markers foreground a verbal, gestural or verbo-gestural metaphor.} Interactive, Semantic and Syntactic Principles

A different type of foregrounding strategy that co-participants in a conversational interaction may employ is a strategy, which operates upon a particular metaphoric expression in order to highlight it. Our guiding assumption for this is: a salient performance foregrounds a verbal or gestural metaphoric expression for an attending co-participant. This is done either by following (a) an Interactive Principle or by following (b) Syntactic and Semantic Principles. While the interactive principle regards the use of particular interactive techniques to achieve a shared focus of attention (cf. Alibali \& Kita 2010; Gulberg \& Kita 2009; Streeck 1988, 1993, 2009), the Syntactic and Semantic Principles concern the integration of gestural metaphoric expressions into the verbal utterance (Fricke 2007b, 2008; Kendon 2004).

\section{a) The Interactive Principle}

We distinguish two forms of foregrounding of a metaphoric expression following the interactive principle (independent of the modality). Either a metaphoric expression is performed in a marked way itself or it is highlighted by a meta-comment realized by another articulator. We have terminologically differentiated these two forms as Internal Interactive Salience Strategies (ILASS) and Extermal Interactive Salience Strategies (ELASS).

Internal Interactive Salience Strategies that speakers use to foreground gestures are cases in which they perform metaphorical gestures so prominently that a co-participant cannot overlook them. Examples would be, for instance, gestures that are performed large and in the focal attentional space of speaker and hearer, such that the listener cannot but see them (cf. Müller 2007, 2008a,b; Streeck 2009). With respect to the verbal modality, Intemal Interactive Salience Strategies may result in metaphoric expressions that are highlighted prosodically. The interactive principle as formulated is in accord with Talmy's common attentional properties of cognitive systems: "greater magnitude along 
a cognitive parameter tends to attract greater attention to the entity manifesting it. This is seen both in language, say, for stronger stress on a linguistic constituent, and in visual perception, say, for lange size [highlighting CM \& ST] or bright color of a viewed object." Talmy 2007: 266).

Here are three forms that we have found in our data in which the speaker has employed Internal Interactive Salience Strategies:

\begin{tabular}{|c|c|}
\hline IIASS $\bullet 1$ & accentuated verbal metaphoric expression \\
\hline IIASS $\sqrt{9} \uparrow$ & large gestural metaphoric expression - hand gesture \\
\hline IIASS B & gestural metaphoric expression in focal space \\
\hline
\end{tabular}

Figure 2. Internal Interactive Salience Strategies realizing the Interactive Principle.

The most prominent example of an Extemal Interactive Salience Strategies is gazing at one's own metaphoric gesture (cf. Alibali \& Kita 2010; Gulberg \& Kita 2009; Streeck 1988, 1993; Müller 2008b). Gaze is one - and maybe even the most - powerful means to direct attention in a conversational interaction. Gazing at things tums them into significant objects of a conversation. When people gaze at their metaphoric gestures, they present them as interactively relevant objects, it shows that the gesture is in the speaker's focus of attention and it invites the listener to share this view (cf. also Goodwin 1981).

Other examples of External Interactive Salience Strategies would be metacommunicative gestures that are performed concurrently with a verbal metaphoric expression: a palm up open hand that presents the verbal metaphoric as evident, or a 'placing' gesture that places a verbal metaphoric expression in the visual space. The two cases of External Interactive Salience Strategies found in the data we are presenting in this article are visually depicted in the following way:

EIASS gaze at the hand
ELASS add Df additional gesture highlighting the metaphoric expression

Figure 3. External Interactive Salience Strategies realizing the Interactive Principle.

b) The Syntactic and Semantic Principle

A syntactic and semantic integration of a gestural metaphoric expression into the verbal utterance highlights the gestural metaphoric expression by making it an obligatory part of a syntactic construction. It might, for instance, be achieved by producing a syntactic gap and/or a speech pause. The speaker may position the gesture into this syntactic gap and into the speech pause and integrate it 
into the utterance structure. Such a use of gesture highlights the metaphoric gesture, by turning it into an obligatory part of the verbal utterance.

Furthermore, speakers may the use deictic particle "like this" to refer to a subsequent metaphoric gesture. This process marks the gesture as semantically relevant and turns it once more into an obligatory part of the utterance. It invites the listener to look at the gesture and to catch the semantic content it expresses at that syntactic position in the utterance (cf. Fricke 2007; 2008; Müller 2008b; Alibali \& Kita 2010; Gulberg \& Kita 2009; Streeck 1988, 1993, 2009). Foregrounding strategies of this kind are termed Syntactic and Semantic Strategies (SSS). The ones that we have identified in the case studies for this article are listed below:

\begin{tabular}{|l|l}
\hline SSS $\overrightarrow{0}$ & syntactic gap through a verbal deictic particle \\
SSS & gesture as direct object
\end{tabular}

Figure 4. Strategies realizing the Syntactic and Semantic Principle.

The following section offers an overview of the analytical steps a Metaphor Foregrounding Analysis entails.

\section{Metaphor Foregrounding Analysis: reconstructing linear and simultaneous temporal patterns of metaphor activation}

For a systematic microanalysis of the metaphor foregrounding strategies that co-participants may employ in a conversational interaction, we have formulated a three-step procedure:

1. Identifying multimodal metaphors in speech and gesture and seeing whether there is more than one metaphoric expression that belongs to one experiential domain or to one domain of meaning (Iconicity Principle).

2. Determining foregrounding strategies operating upon the metaphoric expressions (Interactive, Syntactic and Semantic Principle). This regards primarily simultaneous temporal relations.

3. Determining how foregrounded metaphors evolve in a discourse in steps and clusters and form a foregrounding pattem that uncovers different forms and degrees of activated metaphoricity. This regards linear temporal relations. This third dimension of the analysis includes visualizing the foregrounding strategies by placing the icons for the foregrounding strategies into a time line (i.e. a diagram in which the $\mathrm{x}$-axis depicts the linear progression and the $y$-axis the simultaneous one).

Using the Metaphor Foregrounding Analysis, we can reconstruct a specific kind of embodied dynamics of activated metaphoricity over the course of a conversation. On the one hand this regards the foregrounding of a metaphor at a given moment in time and this is what we call the simultaneous temporal relation. It concems how a given metaphoric expression is highlighted at a specific 
moment in time. This includes all the foregrounding strategies that are employed at one moment in time. For instance, a verbal metaphoric expression is accompanied by a metaphoric gesture, the gesture is performed very large and in the center of the visual attention of the listener. This we regard as an accumulation of foregrounding strategies at one moment in time, or as the simultaneous perspective.

However, a conversation is a continuous flow and in this progression in time, metaphoric expressions might be further elaborated, further foregrounded, they may disappear for a while as the conversation goes on, but then reappear at a later moment in talk. This is what we consider to be the linear temporal relation of foregrounding strategies. When simultaneous and linear analyses come together we can see patterns of foregrounding strategies that participants in a conversation employ. With microanalyses of two sequences of conversational interaction, we will now show what this process looks like.

\section{Microanalyses of different cases of foregrounding and activation of metaphoricity}

In two case studies, we will illustrate how the Metaphor Foregrounding Analysis sketched out above may serve to document the processes of dynamic activation of metaphoricity. We will show how such an analysis of foregrounding steps and clusters forms different foregrounding patterns and hence uncovers different forms and degrees of activated metaphoricity.

Example 1: The course of a love relation as up and down movement. $A$ case of a condensed and mainly simultaneous foregrounding patterm, realized in a short amount of time.

The first example shows a foregrounding of the metaphor love relation as up and down movement in six successive steps. These steps, in tum, build up three foregrounding clusters in which the amount of the simultaneously used foregrounding strategies increases in linear succession. Figure 5 gives a visual representation of these foregrounding steps and clusters. The icons put into a timeline show the foregrounding pattem that emerges in the course of the conversation. They relate precisely to the transcript provided below and to the drawings of the participants' use of gestures and visual attention at the moment in time. 

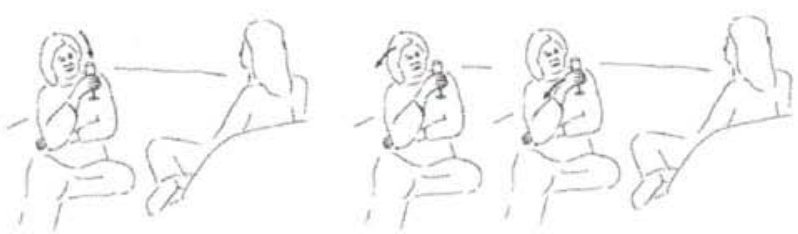

Simultaneous

activetion

actorition
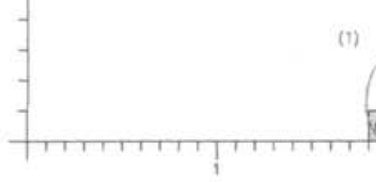

$A$

$J$ A es war eben ein relatives YES it was basically a kind of

aut und ab mit=der mit der standigen tendenz bergAB step $1 \quad$ intanupted step $2 \operatorname{step} 3 \quad$ step 4

HIGHACTIVATION
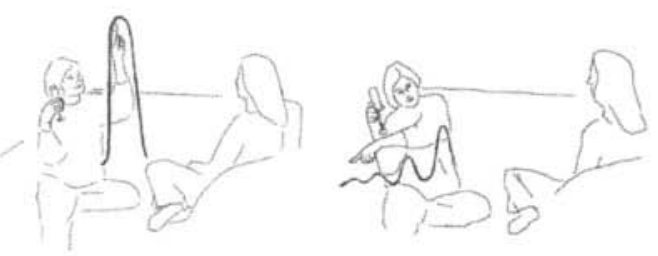

Simulaneous activetion

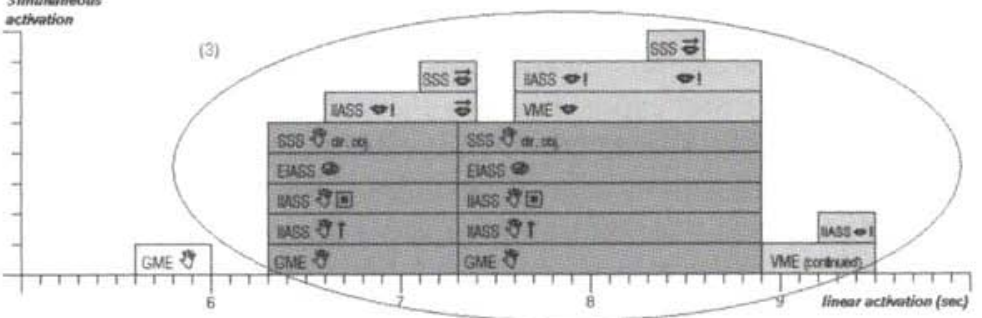

A $(0.4)$ aber os ging (0.3) ne es STARTete so:

und F L A C Hte dann SO: $(0.3)$ wevter $A E$

(0.4) butitwent

$(0,3)$ well it beGAN LIKE THIS:

and FLAttened then LIKE THIS: $(0.3)$ contmuousty OUI

interrupted

step 5

step 6

Figure 5. Example 1. LOVE REI_ATION AS UP AND DOWN MOVEMENT.

The diagram shows that foregrounding activities evolve 'stepwise', i.e. they cluster around metaphoric expressions and these clusters differ with regard to the amount of foregrounding strategies a given speaker employs at a specific 
moment in time. In our example above, the foregrounding strategies employed quickly reach a peak. These foregrounding clusters form a characteristic foregrounding pattem, one that can be characterized as a condensed and mainly simultaneous one. It indicates that the metaphoric expressions used in this short piece of discourse have been successively activated, forming a stepwise progression of activated metaphoricity ranging from onset to increase and ending with two steps of high activation.

We presented the analysis of the example from the back-end, so to say. To really capture what embodied dynamics of metaphor refers to, we need to sketch out the microanalysis from which we derived the above sketched foregrounding pattern in more detail.

Example 1 is taken from a story told in conversation (cf. Müller 2007, $2008 \mathrm{a}, \mathrm{b})$. The speaker summarizes her first relationship, which lasted for several years but which was not easy and contained many highs and lows. These difficulties eventually led to its break-up. She characterizes the course of this love relation as "a kind of up and down", as a path that went up and down many times but had an overall tendency downward. She says:

\section{$J A$ es war eben ein relatives Auf und Ab mit der mit der ständigen Tendenz bergab (1.0 sec) aber es ging (0.3) ne es startete so und flachte dann so (0.3) weiter $a b$}

(YES it was basically a kind of up and down with the with the permanent tendency downhill (1.0) but it went $(0.3)$ well it began like this and flattened then like this ( 0.3$)$ continuously out).

She begins her description with a verbal metaphoric expression: "YES it was basically a kind of up and down". Moreover, when uttering the final part of it ("down") she adds a short downward movement of the head. Taken together, the verbal and the gestural expression form a multimodal metaphor (Cienki \& Müller 2008a,b, Müller \& Cienki 2009; Müller 2008a,b). Metaphoricity provided verbally is foregrounded by a concurrent head gesture, (GME, following the Iconicity Principle). It is the first multimodal metaphor in this sequence (see in figure 5 the circle no. (1)). However, no additional foregrounding strategies are employed here. The head movement is a rather tiny one. This is visually depicted in the graph by only two icons on top of each other: one indicating the verbal part of the metaphor, the other one the gestural part of it. This changes when the speaker proceeds.

In the next steps, she puts more communicative effort into communicating the other spatial momentum of the course of her relationship: it had a permanent tendency downhill ("mit der ständigen tenden 2 berg $A B$ "; "with the permanent tendency DOWNhill"). While she is saying this, she produces several gestures (see in figure 5 the circle no. (2)): a tiny repetition of the downward head gesture used before and a hand gesture moving downward while holding a glass of champagne. Downward directionality is expressed in three modalities simultaneously or in close succession: in words, in a head 
movement, and in a hand gesture. This means that downwardness is being foregrounded following the Iconicity Principle. As companion to these multimodal metaphoric expressions, the speaker employs two additional foregrounding strategies: she gazes at her hand gesture (External Interactive Salience Strategy, EIASS) and she performs the gesture in the center of focal visual attention of the co-participants (Internal Interactive Salience Strategy, IIASS). Taken together, the multimodal metaphoric expression and the additional foregrounding strategies constitute a three further steps in building up a foregrounding pattern. More precisely, they form a cluster of foregrounding strategies that is significantly bigger than the one produced immediately before.

Even though the speaker has now provided a complete picture of the spatial properties of this love relation, she moves on to offer a reformulation of the Up and Down and Downhill structure of the relationship. This further elaboration might be due to a lack of explicit listener ratification of her account. In her next communicative move to get her specific spatial picture of her love relation across, she makes a huge communicative effort to achieve mutual understanding (see in figure 5 the circle no. (3)). How is she doing this? First of all she moves the glass of champagne from her right hand to her left hand. The right hand is now free to gesture without the restriction that holding a glass with champagne puts on the freedom of hand gestures. She then moves on with a verbal deictic construction, pointing towards a gesture she is going to perform: she says: "es STARTete SO" ("it beGAN LIKE THIS"). With this deictic particle she marks the information provided gesturally as an obligatory part of the utterance. This is what we have termed syntactic and semantic integration as foregrounding (or salience) strategy (SSS). The listener is obliged to consider the gesture as a full-fledged part of the verbal utterance; otherwise the sentence would be syntactically incomplete. Moreover the verbal deictic particle is foregrounded through a strong prosodic stress - another way of foregrounding particular parts of the verbal utterance (following the Internal Interactive Salience Strategy, IIASS). In parallel, she performs a large up and down movement with her right hand, which starts high and ends low. The gesture has become a full metaphoric expression of the course of the love relationship that the speaker describes: by pursuing the path of an amplitude (up and down) all the way through, while at the same time starting high up front in the gesture space and ending far down on the right outer edge of the speaker's gesture space, the amplitude gesture blends the two dimensions of meaning that were separated in speech initially: up and down AND downhill. Now this gesture is highlighted by a remarkable set of internal and external foregrounding strategies:

- it is realized as a large hand and arm movement

(Internal Interactive Salience Strategy, ILASS)

- it is performed in the focal attentional space

(Internal Interactive Salience Strategy, ILASS) 
- gaze follows the gestural movement

(External Interactive Salience Strategy, EIASS)

In addition it is verbally highlighted:

- through deictic integration (Syntactic and Semantic Salience Strategy, SSS)

- through prosodic stress (Internal Interactive Salience Strategy, ILASS)

But this is only the first part of this gesturally realized foregrounding of metaphoricity. In the second part of the verbal utterance the speaker accompanies her gestural performance with the words: und FLACHte dann SO (0.3) peiter $A B$ ("and FLAttened then LIKE THIS (0.3) continuously OUT"). During this part of the utterance she is performing a lower-amplitude gesture with a repetitive series of constantly decreasing up and down movements. Here the gestural metaphor that had begun before receives a verbal companion, a verbal metaphoric expression, which leads to further foregrounding (following the Iconicity Principle). The second part of the gestural movement is synchronized with the second part of the verbal utterance. And most of the foregrounding strategies employed before are continued:

- the gestural movement is large and long

(Intemal Interactive Salience Strategy, IIASS)

- it moves out of the focal attentional space

(Internal Interactive Salience Strategy, IIASS)

- but receives the speaker's gaze all the way through (drawing the listeners visual attention to the gesture).

(External Interactive Salience Strategy, EIASS)

In addition, the gesture is also verbally highlighted:

- through co-expressiveness: a verbal metaphoric expression accompanies the gesture (VME, Iconicity Principle)

- through prosodic stress on the metaphoric expression and the deictic particle (Intemal Interactive Salience Strategy, IIASS)

- through deictic integration, another "like this" pointing towards the gesture is employed (Syntactic and Semantic Salience Strategy, SSS)

The diagram illustrates the stepwise increase of strategies that the speaker employs to foreground metaphoricity for her attentive listener. It indicates that moving the metaphoric expressions in words and gestures successively into the foreground of shared attention increasingly activated metaphoricity. Apparently, when regarded from the point of view of an unfolding conversation, metaphoricity appears to be gradable. Means like gaze direction, placing the gesture in the focal attentional space of the co-participant together with lacking of explicit listener feedback and ratification point towards the interactive achievement of a foregrounding pattern, or a salience structure of multimodal utterances. Putting those strategies into a time-line, i.e. taking on not only a micro-analytic but also a sequential or temporal perspective on these 
phenomena indicates the metaphoricity is a dynamic feature of metaphors in language in use. It is dynamic, in that it proceeds over time (linearly) and achieves different degrees of activation (simultaneously), depending on the amount of foregrounding strategies used. It is in this sense that the analysis of the foregrounding patterns allows for an empirical reconstruction of the degrees and temporal arrangements of activated of metaphoricity.

Example 2: personal space as holy aura: $A$ case of a complex simultaneous and linear foregrounding pattern, realized over a longer time span

In contrast to example 1, the second example shows a foregrounding process of a metaphor which emerges out of non-metaphorical meaning. At the beginning of the sequence the speaker expresses a non-metaphorical meaning bodily and verbally: with two hands, he molds a round space around his body, gesturally describing how the situation that he is enunciating felt - he is expressing the feeling of sitting half asleep in a school bus, immersed in his own personal space. At the end of the sequence the co-participants have jointly worked out a verbal metaphoric expression that properly accounts for that particular bodily sensation: the gesturally molded personal space in the school bus was considered a holy aura. The metaphor emerges dynamically over the course of this sequence and can be spelled out as: personal space as holy aura. It is an interactively constructed and highly foregrounded verbo-gestural metaphor in which a concrete target is metaphorically conceptualized via an abstract source: the embodied experience of such bus rides, ie. the sensation of a no-go area surrounding the body of the speaker is seen in terms of a holy aura. We find here an interesting and very untypical case of metaphor construction. Most metaphors discussed in the literature tend to exhibit the following structure: an abstract target is seen in terms of a concrete source. We are referring to examples like europe as building ("Das Haus Europa"), the mind as a machine, or conservatism as strict father model and liberalism as nurturant parent model (Goschler 2008; Lakoff 2002). In our example, however, a sensory target is seen in terms of an abstract concept.

Foregrounding as well as metaphor construction take place in five successive steps (performed by the speaker) as well as through an additional step (performed by the listener). The foregrounding steps constitute four clusters of different sizes and complexity, which are distributed over a relatively long time span (about 20 seconds). Figure 6 gives a graphic representation of these foregrounding steps and clusters. 


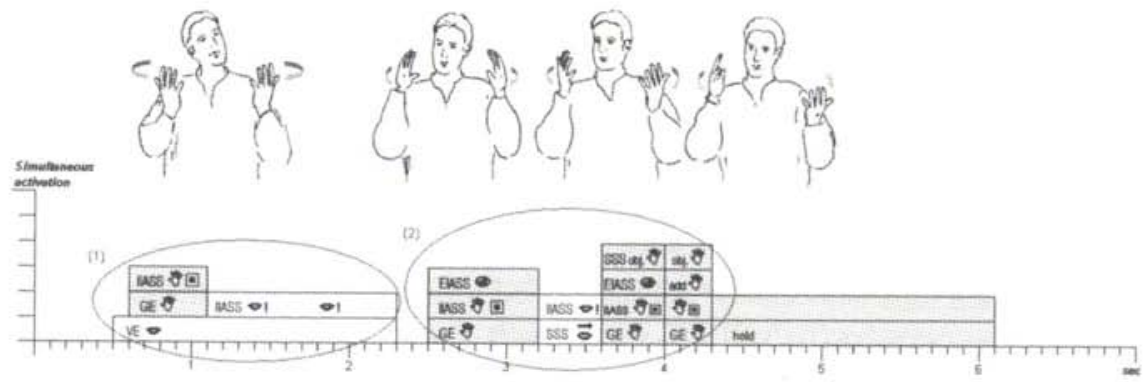

A

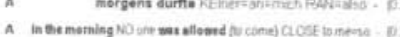

stop 1

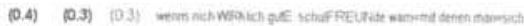

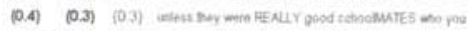

step 3 step 4 fitez 4 nomines

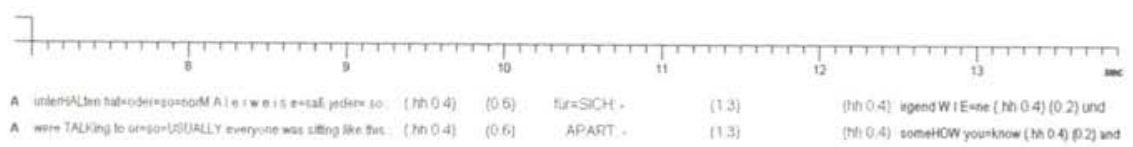

HEGHACTIVATON
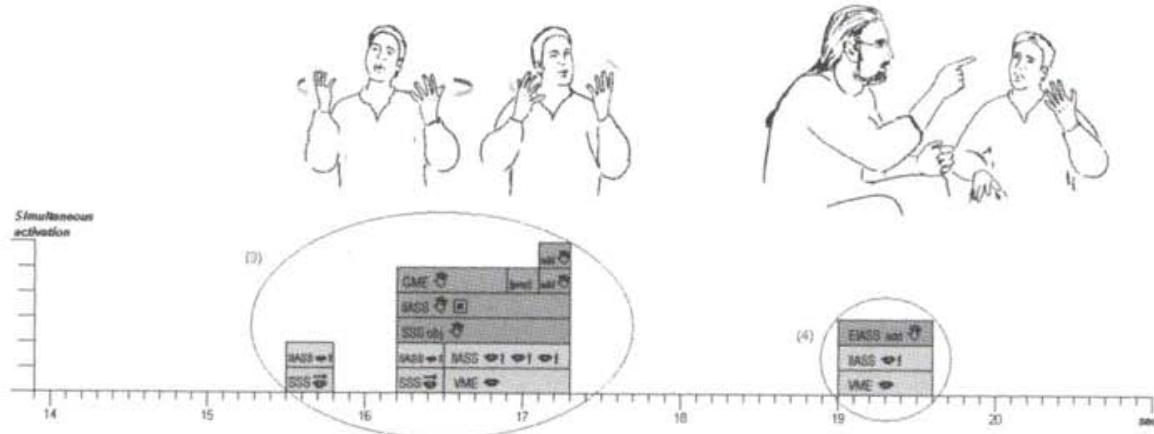

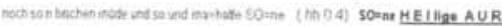

the BLAI Ie midt demath?

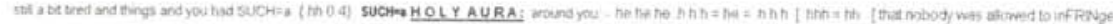

step 6

Figure 6. Example 2. PERSONAL SPACE AS HOLY AURA.

Again, the diagram depicts the foregrounding activities evolving 'stepwise' over the course of the conversation. They cluster around the verbal and gestural expressions which first communicate the concrete bodily sensation and only at the end of the sequence also the abstract metaphoric concept for it. The foregrounding strategies here actually relate to the interactive construction of a 
new metaphor. In this example, the employed foregrounding strategies do not accumulate as quickly as in example 1. They extend over a longer time span and show complex simultaneous and linear foregrounding activities. By doing this, they indicate a stepwise emerging of activated metaphoricity out of a nonmetaphorical meaning. Moreover, the foregrounding pattern includes not only an onset, an increase, and a high activation but also an explicitly interactive activation - becoming manifest in an interactively ratified and co-constructed foregrounding step in the end. This example reveals that when speakers use metaphors in conversation, the metaphors emerge through an embodied, dynamic, and, in particular, interactive construction process.

This extract is taken from the narrative of a young man who describes some of his experiences of growing up and becoming a man. It is part of a longer story in which he describes 'being a cool boy in the school bus'. The speaker begins with a description of a specific bodily sensation that characterizes his feelings during the moming rides in the school bus:

\begin{abstract}
morgens duffte keiner an mich ran also (0.9) so (1.0) wenns nich wirklich gute Schulfreunde wam mit denen man sich unterbalten hat oder so nomalenweise saß jeder so (1.0) für sich (1.7) ingendwie ne (0.6) und noch son bißchen müde und so und man batte so ne (0.4) so ne beilige Aura um sich (lacht) die keiner verletzen durfte ne
\end{abstract}

(in the moming no one was allowed to come close to me so (0.9) like this (1.0) unless they were really good schoolmates who you were talking to or so usually everyone was sitting like this (1.0) apart (1.7) somehow you know (0.6) and still a bit tired and things and you had such a (0.4) such a holy aura around you (laughing) that nobody was allowed to infringe, right).

And while the speaker is finishing his description the listener confirms: "ne Blase weißst du noch" ("a bubble, remember").

This piece of talk is accompanied by a long interrelated sequence of 19 gestures, but we will restrict our focus to those five that are directly related to the illustration of the bodily sensation. ${ }^{8}$ With all of these gestures, the speaker is molding a round space around himself.?

The speaker begins his story with a verbal and gestural description of the situation in the school bus (see figure 6 circle no. (1)). He says: "morgens durfte $K E I n e r$ an mich RAN also" ("in the morning NO one was allowed (to come) CLOSE to me so"). He highlights this first verbal mentioning of his sensation through prosodic stress (following the Internal Interactive Salience Strategy, IIASS) and he accompanies his vocal utterance with a gestural expression (GE). The gestures convey the concept of a round space (following the Iconic Principle): both hands of the speaker mold a roundish space surrounding him

8 For a complete analysis of the example see Tag 2006.

9 For a systematics of the techniques and cognitive-semiotic principles underlying gesture creation, see Müller 1998a,b; Müller 2010a,b; et al. in prep. 
at shoulder height. The gesture is performed in the focal attentional space and thus turned into a salient conversational object for the co-participant (Internal Interactive Salience Strategy, IIASS). This gesture indicates the beginning activation of the embodied concept of 'personal space as round space' that will become the target of the verbo-gestural metaphor later on: personal space as holy aura. It provides empirical evidence that the general idea "nobody was allowed to come close to me" is conceptualized via the body as an ephemeral round space surrounding the speaker. We may thus infer that the target of the metaphor "personal space surrounding speaker in his school bus rides in the moming as holy aura", which the speaker later formulates vocally, is activated at this moment in time. Also, by synchronising with the verbal description, this gesture marks the onset of the embodied meaning activation.

In cluster 2 (see figure 6, circle no. (2)) we see an increasing foregrounding of the concept of 'round space around the speaker'. This is achieved by three foregrounding steps in which the speaker pauses and interrupts his storytelling, but produces three repetitions of the 'round-space gesture'. Each of these gestures is a slightly different version of the initially performed gesture in the first cluster.

The first repetition (GE in step 2, foregrounding following the Iconic Principle) again shows the round space, but this time, both hands mold only its lateral sides. The gesture is highlighted by two additional strategies: it is performed in the focal attentional space and therefore is unlikely to have been overlooked by an attending co-participant (Intemal Interactive Salience Strategy, IIASS). In this central location, the gesture receives the speaker's gaze, interactively attracting the attention of the listener (External Interactive Salience Strategy, EIASS).

Then the speaker produces a verbal deictic particle ("like this"). This particle is used to foreground cataphorically the upcoming gestural expression of the concept: by means of "like this" the speaker integrates the gesture semantically and syntactically into his utterance (Syntactic and Semantic Salience Strategy, SSS). The particle is additionally highlighted through prosodic stress (Internal Interactive Salience Strategy, IIASS). The following gesture is a second repetition and almost an exact copy of the initially performed 'round space gesture' (GE in step 3, foregrounding following the Iconic Principle). It is interactively foregrounded once again by performing it in the focal attentional space (Internal Interactive Salience Strategy, IIASS). In addition, the speaker continues to gaze at his gesture, foregrounding it via the External Interactive Salience Strategy.

Immediately afterwards, the speaker arranges a very explicit foregrounding of the 'round-space gesture'. While molding once again one of the lateral sides of the round space with his right hand (GE in step 4, following the Iconicity Principle), he simultaneously uses his left hand to perform an additional gesture: the left hand presents on its open palm the very concept of the round personal space embodied with the right hand as a significant conversational 
object to his listener (External Interactive Salience Strategy, EIASS). ${ }^{10}$ The two simultaneously produced gestures continue to be performed in focal attentional space (Internal Interactive Salience Strategy, IIASS). In sum, because the second foregrounding cluster comprises significantly more simultaneously and linearly arranged strategies than cluster 1 , it indicates a significant increase of activation of the specific meaning in question.

Neverthless, even though the speaker makes this big communicative effort to attract the attention of his listener to the embodied idea of the round space repeating and presenting the round space gesture(s), the addressed coparticipant, being busy with enjoying a piece of cake, does not give any visual, auditory or bodily affirmation of attendance. From an interactive point of view, the gestural foregrounding of the underlying concept fails, due to a lack of listener feedback or ratification. This indicates that the multimodal foregrounding of metaphoricity is rooted in an Interactive Principle. Foregrounding is - at least partly - done for and with an attending coparticipant.

Thus, without ratification from his conversational partner, the speaker does not feel encouraged to continue the activity of foregrounding the 'round-space concept'. This is where he interrupts his foregrounding activities. Despite the short phase in which one hand still maintains the expression of the concept of the round space around the speaker, we see a break-off of foregrounding activities that relate to the round space idea. Instead, the speaker produces a long side-sequence of nine seconds (which is nearly $45 \%$ of the entire example). During this side-sequence, he makes no further effort to express or foreground this concept. Instead, he provides further contextual information regarding the specific situation and experience of being in the school bus:

\section{wenns nich wirklich gute Scbulfreunde warn mit denen man sich unterhalten bat oder so normalerweise saß jeder so (1.0) für sich (1.7) ingendwie ne (0.6) und noch son bißchen müde und so}

(unless they were really good schoolmates who you were talking to or so usually everyone was sitting like this (1.0) apart (1.7) somehow you know (0.6) and still a bit tired and things).

This side sequence contains 14 gestures - none of them is used to foreground the concept of a round space. The break-off and the subsequent side-sequence document that the emergence of metaphoric meaning is highly dependent on the interactive feedback of a co-participant. It is not just that the speaker intends to convey some specific metaphor, it is that he tries to find a way to frame his idea of the sensations in the school bus in such a way that his coparticipant understands and expresses this understanding (this is what

10 For work on simultaneous forms of gesture combinations, see Tag 2006, Tag in prep. a. More on the open palm gesture, technically PUOH: Müller 2004; Kendon 2004. 
conversation analysts call recipient design and the co-construction of utterances or what Herb Clark calls 'common ground' in conversation). And indeed, the speaker starts a second and even bigger attempt to get his round-space idea across.

Now we observe the core of the foregrounding activities in cluster 3 (see figure 6 , circle no. (3)). The speaker creates a multimodal metaphor which conceptualizes the idea of a personal round space as an invisible holy aura surrounding himself. With a fresh repetition of the 'round-space gesture', the speaker provides the concrete metaphoric target once again bodily. ${ }^{11}$ But now, he verbally presents an abstract source for this bodily sensation in the school bus. He says: "und man hatte SO ne SO ne HEIlige AURA um sicb" ("and you had SUCH a SUCHa HOL, AURA around you'). At the same time, he repeats the round space gesture. This is the point of emergence of a multimodal metaphor. personal space as holy aura.

What we see here is a very interesting case of metaphor emergence or metaphor construction. The target (or topic) and source (or vehicle) are detached from each other, and it is only by taking into account the dynamic process of utterance construction, i.e. by closely considering the sequential structure of the multimodal utterance over a longer time span, that we are able to identify that a metaphor was produced and that we can determine what is its source (vehicle) and what is its target (topic).

But how does a "holy aura" relate to the bodily sensation of a round space surrounding the speaker sitting in his school bus? In metaphysics, an "aura" denotes an energy field that surrounds a living being. It appears therefore that the speaker uses a verbal expression referring to an abstract concept as a metaphoric source (or vehicle) to explain the target (topic) of a concrete bodily sensation - the round space around him. Only now the multimodal metaphor is fully expressed in two modalities, constituting the core of the foregrounding cluster (3) following the Iconicity Principle (verbal and gestural metaphoric expression (VME and GME) in step 5). What evolves in cluster 3 is a complex verbo-gestural performance, which is highlighted by several additional foregrounding strategies. The verbal part of the utterance contains:

- two deictic particles pointing towards the multimodal metaphor

(repeated use of the Syntactic and Semantic Salience Strategy, SSS)

- the two deictic particles receive strong prosodic stress

(Internal Interactive Salience Strategy, ILASS)

- the verbal metaphoric expression receives strong prosodic stress

(Intemal Interactive Salience Strategy, IIASS).

The both-handed moulding of the round space is highly interactively foregrounded, too.

11 This form of taking up a gesture at different points of a discourse reminds of McNeill's and Duncan's idea of catchment (McNeill et al. 2001). 
- it is performed in focal attentional space (Internal Interactive Salience Strategy, IIASS, ie. simultaneous foregrounding)

- it is followed by two simultaneously produced one-handed gestures, adding a successive, linear foregrounding of the previously expressed multimodal metaphor:

$\Rightarrow$ the right hand makes a short downward movement, i.e. an intensifying beat gesture (External Interactive Salience Strategies, EIASS)

$\Rightarrow$ the left hand presents with a palm up open hand the multi-modal metaphor as an obvious one, and invites his co-participant to join in this perspective

(Extemal Interactive Salience Strategies, EIASS)

This third cluster of densely packed foregrounding strategies arranged simultaneously and in linear succession indicates a bigh degree of embodied activation of meaning. The activated meaning, moreover, has turned into a metaphoric meaning now.

Finally, the big expressive effort has the desired interactive effect (see figure 6 , circle no. (4)). The speaker's conversational partner moves his attention away from enjoying his cake, to the topic of the conversation. He shows explicitly that and how he has understood the idea of the round space surrounding the speaker on his bus rides. He does this by bringing in yet another verbal metaphoric expression with which he reformulates the multimodal metaphor personal space as holy aura as a kind of bubble. He says: "ne BLASe weift dx nocb" ("a BUBBle, remember"). This is an interesting case, because the first speaker expresses the metaphoric target (1.e. the multimodal metaphor personal SPACE AS holy aura) while the listener is providing a new metaphoric source (vehicle) (personal space as holy aura as bubble). The listener explicates his understanding of the multimodal metaphor by actually creating a new verbal metaphoric expression and in this way interactively ratifies the multimodal metaphor formulated by the speaker.

We would like to suggest that this metaphor has actually one more target (or vehicle) - the verbal metaphoric expression "holy aura", just mentioned before. With this new metaphoric expression the listener of the story offers the ratification or confirmation of the multi-modal metaphor "personal space as holy aura" that the speaker has put so much expressive effort into to get across. This last foregrounding cluster is thus fully co-constructed. By simultaneously using two additional foregrounding strategies the listener makes sure that everybody gets what he is saying:

- the verbal metaphoric expression is highly accentuated (Internal Interactive Salience Strategy, IIASS),

- it is temporally synchronized with an upward pointing gesture, i.e. a gestural attention-getting marker

(Extemal Interactive Salience Strategy, EIASS). 
This fourth cluster marks the end of the dynamic construction and foregrounding of a metaphoric meaning. Here, a multimodal metaphor is foregrounded by producing a further metaphoric expression, used to express mutual understanding and to ratify the multimodal metaphor, which needed a fairly long way to actually emerge in the conversation. In this last step, we see an explicit interactive activation of metaphoricity, which emphasizes once more that in actual language use the dynamic process of embodied activation of meaning and metaphoricity is not restricted to the activities of the speaker alone but is a truly inter-active affair.

\section{Summary: Microanalysis of two examples}

Both examples show a dynamic foregrounding of metaphoric content - and hence a dynamic and interactively grounded activation of metaphoricity that expands over different time spans and shows different forms and degrees.

Already with regard to the construction of the multimodal metaphors (i.e. the structure of the core foregrounding strategies), both examples show considerable differences: whereas in the first example ('love relation'), a multimodal metaphor constitutes the onset of the dynamic process of foregrounding metaphoricity, in the second example ('holy aura'), the multimodal metaphor only emerges over a longer time span, starting out with the foregrounding of a non-metaphoric meaning, which turns into the target of a multimodal metaphor later on as the conversation proceeds. Also, while in the first case we find a 'classical' case of a 'concrete' source being mapped onto an 'abstract' target (movement in space for the course of a love relation), in the second case it is the other way around: a 'concrete' sensory target (the personal space) is being conceptualized by an abstract source (the holy aura) (holy aura for personal space). Without a sequential microanalysis the second case would probably never have been identified as a metaphor at all, because the source is provided so much later in the discourse than the target.

Both examples also differ with regard to their respective foregrounding patterns. The first case is characterized by a condensed and mainly simultaneous foregrounding pattern, with a steady and fast increase of foregrounding of metaphoricity realized in a short amount of time. Meanwhile, the second example shows a highly complex simultaneous and linear foregrounding pattern that extends over a longer time span. This means that in the love relation' sequence a big expressive effort is realized in a short amount of time, in the 'holy aura' example the expressive effort extends over a rather long time span and is even temporarily interrupted due to a lack of listener feedback. The multimodal metaphoric expressions that will eventually be created by both co-participants appear to be truly interactive products; both speaker and addressee of the story provide their own metaphoric reading of the initially foregrounded meaning. The 'holy aura' example eventually is characterized by a big collection of both simultaneously and linearly arranged strategies within the foregounding clusters - mirroring the longer temporal 
extension of the dynamic construction of this multimodal metaphor. This format contrasts sharply with the mainly simultaneous use of foregrounding strategies in the first example. Those strategies reflect a fast and short foregrounding of metaphoricity that is achieved primarily by the speaker.

\section{Conclusion: Empirically reconstructing the dynamic foregrounding and activation of metaphoricity in conversation}

Language in use is the natural home of metaphor. When we examine metaphor in its natural environment, we find that metaphors may be foregrounded in various ways, indicating different forms and degrees of activated metaphoricity. Moreover, speakers may use an array of strategies to wake metaphors up and foreground them in the discourse. These 'foregrounding strategies' display the expressive effort that speakers - or more generally that co-participants in an interaction - employ to mark metaphoricity as a salient object of attendance in the flow of a conversation. On the other hand it appears that these foregrounding strategies are not restricted to foregrounding metaphoricity. As the 'holy aura' example indicates they are general strategies that may operate on any aspect of meaning in an ongoing utterance. And as such the foregrounding principles as well as their respective strategies introduced in this article are to be conceived of as first steps towards a cognitive-linguistic and micro-analytic methodology that reconstructs the temporal and dynamic orchestration of meaning in multimodal utterances.

Our analyses of the examples point towards a dynamic nature of conceptualization and they recall Langacker's claim of a dynamic and temporally organized nature of conceptualization (Langacker 2001, 2008).

Conceptualization is inherently dynamic. It resides in mental processing, so every conception requires some span of processing time - however brief - for its occurrence. In principle, of course, the temporal aspect of conceptualization might turn out to be irrelevant for linguistic meaning. It might be hypothesized that conceptual configurations are evoked holistically and are stable for the duration of their activation. Altematively, it might be claimed that such configurations are arrived at through processing activity which is not itself linguistically relevant - only the final product has any significance. I will argue, however, that dynamicity is essential to linguistic semantics. How a conceptualization develops and unfolds through processing time is often (if not always) a pivotal factor in the meanings of expressions. (Langacker 2001: 8)

The successive emergence of metaphoricity indicates that a processing individual does not necessarily evoke metaphoric meaning holistically at one moment in time, nor does it appear to be very stable across time. Rather we observe a flow of foregrounding metaphoric meaning, with peaks and dips, constructed in a permanent flow of conversational interaction. Our observations are therefore in line with Langacker's dynamic view on conceptu- 
alization, while at the same time extending his assumptions to meaning construction in conversational interactions.

For metaphor studies, the kind of strictly sequential analysis proposed here uncovers new forms of metaphors, forms that a traditional word-by-word analysis is unable to detect, simply because of their sequential structure (as for example in the 'holy aura' case). Moreover the methodology presented in this article, offers a way to empirically determine whether metaphoricity of a given verbal or gestural metaphoric expression has been activated for a given speaker and sometimes also for a given listener at a specific moment in time. Of course this only holds for those instances in which metaphors are foregrounded. It is important to underline that we cannot exclude that a speaker who foregrounds any other aspect of meaning in a given utterance does not activate metaphoricity expressed somewhere. But what we can say is that if metaphoricity is dynamically foregrounded in the way that we have seen it in the examples (verbal and gestural elaborations highlighted by additional foregrounding activities), it is very likely that it is also cognitively activated. Experimental studies would have to provide hard empirical evidence for this theoretically motivated claim.

What we can reconstruct by a metaphor foregrounding analysis is the cognitive activation understood as a constantly moving focus of attention. In this sense the argument and the method presented in this article are very much in line with Wallace Chafe's approach to describing the flow of consciousness through an analysis of intonation units. However, we suggest that in these foregrounding activities of conversational partners we observe an interactively negotiated flow of attention. Foregrounding directs attention and cognitive activation is understood here as the constantly moving focus of attention.

As discourse is constantly progressing through time, so is attention, but not only does it flow constantly - it flows selectively - as one could say. It flows selectively from attentional focus to attentional focus, making constant choices as to what are the most important aspects of an utterance (in Oakley's terms this is the directing aspect of attention, Oakley 2008: 28). Now, what is of importance, may be due to intra-personal as well as to inter-personal factors since when we talk, we always talk to somebody, we address somebody verbally and bodily, and our utterances are always shaped by the requirements of the particular interactional situation we are in. A long time ago, conversation analysts identified this phenomenon and termed it recipient design (Sacks et al. 1974). Chafe's theory of the flow of consciousness in discourse takes another view on that issue (Chafe 1994, 1996), and Oakley (2008: 27) captures a similar dimension with his concept of an interpersonal system of attention (sharing and barmonizing attention). Talmy also builds his take on attention phenomena on the speech situation: ${ }^{12}$

12 For a summary of cognitive linguistic approaches to attention see Croft and Cruse 2004. 
In a speech situation, a hearer may attend to the linguistic expression produced by a speaker, to the conceptual content represented by that expression, and to the context at hand. But not all of this material appears uniformly in the foreground of the hearer's attention. Rather, various portions or aspects of the expression, content, and context have differing degrees of salience [...]. Such differences are only partially due to any intrinsically greater interest of certain elements over others. More fundamentally, kanguage has an extensive system that assigns different degrees of salience to the parts of an expression or of its reference or of the context. In terms of the speech participants, the speaker employs this ystem in formulating an expression; the hearer, largety, on the basis of such formulations, allocates bis or ber attention in a particular way over the material of these domains. (Talmy 2007: 264, highlighting CM \& ST)

Our approach contributes a further perspective to Talmy's picture of the speech-situation. We suggest that it is not only the attentional system of language that triggers and guides the flow of attention, but also the specific properties of language in communication as a social, cognitive and affective enterprise. Departing from language in use means taking into account the dynamic and multimodal nature of utterances.

We hope to have successfully illustrated that investigating metaphors in conversational interactions uncovers different dynamic foregrounding pattems - indicating that the activation of metaphoricity is not a static one-item issue, but rather a complex dynamic and embodied process orchestrated by the flow of attention as time moves on. As Talmy (2007: 266) notes:

In terms of the qualities of attention per se, linguistic attention functions as a gradient, not as a dichotomous all-or-none phenomenon. The particular level of attention on a linguistic entity is set in terms of foregrounding or backgrounding relative to a baseline for the entity, rather than absolutely on a zero-based scale. And the linguistic aspects realized in the course of a discourse range along a gradient of "access to attention," from ones with "interruptive" capacity, able to supplant whatever else is currently highest in attention, to ones that basically remain unconscious.

Attention is a dynamic process, which as far as metaphoric expressions are concerned results in a gradient structure of activated metaphoricity. This article presents a method that helps to uncover the very flexible nature of metaphorical expression and metaphorical thinking, and offers a tool to detect these special cases of multimodal metaphors.

We hope to have provided some support for the dynamic view of sleeping and waking metaphors as advanced by Müller (2008a) and to have shown how it can be further developed both with regard to a methodology that provides 'thick descriptions' of dynamic processes of metaphor activation and with regard to bridging it to the more general question of attention.

Attention emerges from this article as a major cognitive process orchestrating and imprinting language as it is used in spoken discourse. For 
theories of metaphor, the dynamic view offers a new take on the identification of metaphors as activated or waking ones in conversational settings. Taking language use as a point of departure and taking the dynamic process of metaphor activation as the core cognitive activity that brings metaphor to life, the dynamic view holds that a sleeping metaphor only carries a potential for activation - and hence a potential for metaphor. The paradox of metaphor - as formulated by Steen (2008) - dissolves when considering the sequential and multimodal nature of metaphors in language use. It turns into a merely empirical question of determining whether or when a given metaphor is actually activated in language use. From a cognitive-linguistic point of view the interactive theoretical and methodological take advanced in this paper offers an intersubjectively accountable methodology to identify waking metaphors, to precisely trace activated metaphoricity in the flow of a discourse - and by doing this it gets an empirical hold on the all three dimensions of Oakley's Greater Attention System: the signal system, the selection system and the interpersonal system (Oakley 2008).

But there is more to the dynamic flow of multimodal utterances than attention as a purely cognitive perceptual phenomenon. The very fact that a speaker embodies part of his utterance transforms this utterance into a sensory experience for both the speaker and the addressee. This sensory experience entails conceptualizations, points of view but also affective qualities inherent to these embodiments of meaning (Gibbs 1994, 2006). The clusters and pattems of activated metaphoricity that we have documented in this paper are comparable to what film studies has described as expressional movement of a film (Eisenstein \& Tretyakov 1922/1996; Kappelhoff 2004, 2008a,b). In spoken discourse they are spontaneously and interactively constructed expressional movements, while in films they are artfully composed audio-visual structures including: camera perspective, camera movement, sound, montage, color.

The micro-analysis of multimodal metaphors in spoken discourse thus reveals that metaphor entails the possibility for an embodied, dynamic ad hoc form of experience - brought into play in the flow of discourse, pointing towards a close intertwinement of cognition, affect, and interaction with worldly or cultural matters:

The inseparability of mind, body, and world, and of cognitive and cultural models, points to the important idea that metaphor is an emergent property of body-world interactions, rather than arising purely from the heads of individual people. We need not talk of metaphor as only part of our mental representations for concepts (e.g. anger), or as expressed by language (e.g. She bursted with anger.) Metaphor is a kind of tool that arises from body-world interactions, which we can "re-experience" in an embodied way, and is not simply accessed from longterm memory, in different ways in different real-world situations. As Krimayer (1992:335) phrased it: "metaphors are tools for working with experience." (Gibbs 1999: 156) 


\section{Acknowledgements}

We would like to thank two anonymous reviewers for extremely helpful comments on an earlier version of this article. Alan Cienki, Helmut Hinck, Simon Harrison, Henning Tag did meticulous work on the manuscript at various stages of its production and we are extremely grateful for their multifaceted support.

\section{References}

Alibali, M. W. \& Kita, S. (2010). Gesture highlights perceptually present information for speakers. Gesture, 10 (1), 3-28. <http://dx.doi.org/10.1075/gest.10.1.02ali>, last access on 26.10.2010.

Allen, S., Özürek, A., Kita, S., Brown, A., Furman, R., Ishizuka, T. \& Fuji M. (2007). How language specific is early syntactic packaging of Manner and Path? A comparison of English, Turkish, and Japanese. Cognition, 102, 16-48.

Barsalou, L. W. (1999). Perceptual symbol systems. Behavioral and Brain Sciences, 22, $577-$ 660.

Cameron, L. J. (1999). Identifying and describing metaphors in spoken discourse data. In L. J. Cameron \& G. Low (Eds.), Researcbing and Appbring Metaphor (pp. 105-132). Cambridge: Cambridge University Press.

Cameron, L. J. (2007). Patterns of metaphor use in reconciliation talk. Discourse and Society, 18 (2), 197-222.

Cameron, L. J., Maslen, R, Todd, Z., Maule, J., Stratton, P. \& Stanley, N. (2009). The discourse dynamics approach to metaphor and metaphor-led discourse analysis. Metaphor and Symboh, 24 (2), 63-89.

Cameron, L. J. \& Low, G. (Eds.) (1999). Researrbing and Appbing Metaphor. Cambridge: Cambridge University Press.

Casasanto, D. \& Jasmin, K. (2010). Good and Bad in the Hands of Politicians: Spontaneous gestures during positive and negative speech. PLOS ONE, 5 (7), e11805.

Casasanto, D. (2009). Embodiment of Abstract Concepts: Good and bad in right- and left-handers. Joumal of Experimental Psychology: General, 138 (3), 351-367.

Chafe, W. (1994). Discourse, Consciousness, and Time. The Flow and Displacement of Conscious Experience in Speaking and Writing. Chicago and London: University of Chicago Press.

Chafe, W. (1996). How Consciousness Shapes Language. Pragmatios and Cognition, 4 (1), $55-64$.

Cienki, A. (2008). Why Study Metaphor and Gesture. In A. Cienki \& C. Müller (Eds.), Metaphor and Gesture (pp. 5-25). Amsterdam/Philadelphia: John Benjamins.

Cienki, A. \& Müller, C. (Eds.) (2008a). Metaphor and Gesture. Amsterdam/Philadelphia: John Benjamins.

Cienki, A. \& Müller, C. (2008b). Metaphor, gesture and thought. In R. W. Gibbs, Jr. (Ed.), The Cambridge handbook of metaphor and thought (pp. 484-501). Cambridge: Cambridge University Press.

Clark, H. H. (1996). Using language. Cambridge: Cambridge University Press.

Croft, W. \& Cruse, D. A. (2004). Cognitive Linguistics. Cambridge: Cambridge University Press. 
Duncan, S. D. (2002). Gesture, verb aspect, and the nature of iconic imagery in natural discourse. Gesture, 2 (2), 183-206.

Duncan, S. D. (2006). Co-expressivity of speech and gesture: Manner of motion in Spanish, English, and Chinese. In Proceedings of the 27th Berkeley Linguistic Society Annwal Meeting (pp. 353-370). Berkeley, CA: Berkeley University Press.

Duncan, S. D., Cassell, J. \& Levy, E. (Eds.) (2007). Gesture and the dynamic dimension of language. Essays in bonor of David McNeill. Amsterdam/Philadelphia: John Benjamins.

Eisenstein, S. M. \& Tretyakov, S. ([1922] 1996). Expressive Movement. In A. Law \& M Gordon (Eds.) Meyerbold, Eisenstein and Biomechanics - Actor Training in Revolutionary Russia (pp. 173-192). London: McFarland.

Forceville, C. (1998). Pictorial Metaphor in Advertising. London/New York: Routledge.

Forceville, C. (2002). The identification of target and source in pictorial metaphors. Joumal of Pragmatics, 34 (1), 1-14.

Forceville, C. (2004-2009). A Course in Pictorial and Multimodal Metaphor. Semiotics Institute Online. <www.chass.utoronto.ca/epc/srb/cyber/cyber.html>, last access on 1.11.2010.

Forceville, C. (2006). Non-verbal and multimodal metaphor in a cognitivist framework: Agendas for research. In G. Kristiansen, M. Achard, R. Dirven \& F. Ruiz de Mendoza Ibáñez (Eds.), Cognitive Linguistics: Cument Applications and Future Perspectives (pp. 379-402). Berlin/New York: Mouton de Gruyter.

Forceville, C. \& Urios-Aparisi, E. (Eds.) (2009). Multimodal Metaphor. Berlin/New York: Mouton de Gruyter.

Fricke, E. (2007). Where is here? The analysis of the German deictic 'hier' with cospeech pointing gestures. In L. Mondada (Ed.), Gestures and the Organization of Social Interaction: Ethrometbodological and Conversational Perspectives. Proceedings of the 2nd Conference of the International Society for Gesture Studies (ISGS). gesture-lyon2005.enslsh.fr/article.php3?id_article $=259$

Fricke, E. (2008). Grundlagen einer multimodalen Grammatik des Deutschen: Syntaktische Strukturen und Funktionen. Ms., Habilitation, European University Viadrina Frankfurt (Oder).

Fuchs, T. (2006). Leibgedächtnis und Lebensgeschichte. Konzentrative Bewegungstherapie $28,24-33$.

Fuchs, T. (2008). Laib und Lebenswelt. Neue philosophisch-psychiatrische Essays. Kusterdingen: Die Graue Edition.

Fuchs, T. (2009). Embodied Cognitive Neuroscience and its Consequences for Psychiatry. Poiesis and Praxis, 6, 219-233.

Fuchs, T. \& De Jaegher, H. (2009). Enactive intersubjectivity: Participatory sensemaking and mutual incorporation. Phenomenology and the Cognitive Sciences 8, 465-486.

Fuchs, T. \& Mundt, C. (Eds.) (in prep.). Time, memory and the self. Contributions from phenomenology, psychopathology and the neurosciences. Oxford: Oxford University Press.

Gallagher, S. (2005). How the body shapes the mind. Oxford: Oxford University Press.

Gibbs, R. W., Jr. (1994). The Poetics of Mind: Figurative Thought, Language, and Understanding. Cambridge, UK: Cambridge University Press.

Gibbs, R. W., Jr. (1998). The Fight over Metaphor in Thought and Language. In A. N. Katz, C. Cacciari, R. W. Gibbs, Jr. \& M. Tumer (Eds.), Figurative Language and Thought (pp. 119-57). New York and Oxford: Oxford University Press.

Gibbs, R W., Jr. (1999). Taking metaphor out of our heads and putting it into the cultural world. In Gibbs, R. \& Steen, G. J. (Eds.), Metaphor in Cognitive Linguistics (pp. 145-166). Amsterdam: John Benjamins. 
Gibbs, R. W., Jr. (2006). Embodiment and Cognitive Science. New York: Cambridge University Press.

Gibbs, R. W., Jr. \& Cameron, L. J. (2008). The social cognitive dynamics of metaphor performance. Cognitive Systems Researth, 9 (1-2), 64-75.

Gibbs, R. W., Jr. \& Steen, G. J. (Eds.) (1999). Introduction. In R. W. Gibbs, Jr. \& G. J. Steen (Eds.), Metaphor in Cognitive Linguistics (pp. 1-8). Amsterdam: John Benjamins.

Giora, R. (1997). Understanding figurative and literal language: The graded salience hypothesis. Cognitive Linguistics, 8 (3), 183-206.

Giora, R. (2002). Literal vs. figurative language: Different or equal? Jourmal of Pragmation, 34, 487-506.

Giora, R. (2003). On our mind: Salience, context, and figurative language. New York: Oxford University Press.

Goschler, J. (2008). Metaphern für das Gebirm. Eine kognitiv-linguistiscbe Untersuchung. Berlin: Frank und Timme.

Goodwin, C. (1981). Conversational Organization: Interaction Between Speakers and Hearers. New York: Academic Press.

Goodwin, C. (2000). Practices of Seeing, Visual Analysis: An Ethnomethodological Approach. In T. v. Leeuwen \& C. Jewitt (Eds.), Handbook of Viswal Anabysis (pp. 157-82). London: Sage.

Goodwin, C. (2003). The Body in Action. In J. Coupland \& R. Gwyn (Eds.), Discourse, the Body and Identity (pp. 19-42). New York: Palgrave/Macmillan.

Goodwin, C. (2007). Environmentally Coupled Gestures. In S. Duncan, J. Cassell \& E. Levy (Eds.), Gesture and the Dynamic Dimensions of Language (Pp. 195-212). Amsterdam/Philadelphia: John Benjamins.

Gullberg, M. \& Kita, S. (2009). Modulating addressees' attention to speechaccompanying gestures: Eye movements and information uptake. Joumal of Nonverbal Bebavior, 33 (4), 251-277.

Johnson, M. (2007). The meaning of the body. Aesthetics of buman understanding. Chicago: The University of Chicago Press.

Kappelhoff, H. (2004). Matrix der Gefüble. Das Kino, das Melodrama und das Theater der Empfindsamkeit. Berlin: Vorwerk 8.

Kappelhoff, H. (2008a). Die Anschaulichkeit des Sozialen und die Utopie Film. Eisensteins Theorie des Bewegungsbildes. In G. Boehm, B. Mersmann \& C. Spies (Eds.), Movens Bild. Zurischen Evidenz und Affekt (pp. 301-324). München: Wilhelm Fink Verlag.

Kappelhoff, H. (2008b). Realismus: das Kino und die Politik des Ästhetischen. Berlin: Vorwerk 8.

Kappelhoff, H. \& Müller, C. (in prep.). Multimodal metaphor and expressional movement. A model of dynamic orientation of affect in spoken discourse, TVcoverage, TV series and fictional films. Metaphor in the Social World.

Katz, A. N., Caciarri, C., Gibbs, R.W., Jr. \& Tumer, M. (1998). Figurative Language and Thought. New York and Oxford: Oxford University Press.

Kendon, A. (2004). Gesture: Visible Action as Utterance. Cambridge: Cambridge University Press.

Kita, S. \& Ozyürek, A. (2003). What does cross-linguistic variation in semantic coordination of speech and gesture reveal?: Evidence for an interface representation of spatial thinking and speaking. Joumal of Memory and Language, 48, 16-32.

Koch, S. C., Fuchs, T. \& Müller, C. (Eds.) (in prep.). Body Memory, Metaphor and Movement. New York: John Benjamins. 
Kyratzis, S. (2003). A new metapbor for metaphor. Evidence for a single dymamic metaphorical category. Ms.

Ladewig, S. H., Müller, C. \& Teßendorf, S. (2010). Structures of menning and neference. How the concrete becomes abstract. Talk given at GESPIN 2009, Sept. 23-26, Poznan.

Lakoff, G. (2002). Moral Politics: How Liberals and Conservatives Think Chicago: University of Chicago Press.

Langacker, R. W. (2001). Dynamicity in Grammar. Axiomathes, 12, 7-33.

Langacker, R. W. (2008). Metaphoric Gesture and Cognitive Linguistics. In A. Cienki \& C. Müller (Eds.), Metapbor and Gesture (pp. 249-251). Amsterdam/Philadelphia: John Benjamins.

Larsen-Freeman, D. \& Cameron, L. J. (2008). Research methodology on language development from a complex systems perspective. Modem Language Joumal, 92 (2), 200-213.

McNeill, D. (1992). Hand and Mind: What Gestures Reveal about Thought. Chicago: University of Chicago Press.

McNeill, D., Quek, F., McCullough, K.E., Duncan, S., Furuyama, N., Bryll, R., Ma, XF. \& Ansari, R. (2001). Catchments, prosody and discourse. Gesture, 1, 9-33.

McNeill, D. (2005). Gesture and Thought. Chicago: University of Chicago Press.

Mittelberg, I. (2008). Peircean Semiotics Meets Conceptual Metaphor: Analyses of Gestural Representations of Grammar. In A. Cienki \& C. Müller (Eds.), Metaphor and Gesture (pp. 145-184). Amsterdam/Philadelphia: John Benjamins.

Mittelberg, I. \& Waugh, L. R. (2009). Metonymy first, metaphor second: A cognitivesemiotic approach to multimodal figures of speech in co-speech gesture. In C. Forceville \& E. Urios-Aparisi (Eds.), Multimodal Metaphor (pp. 322-356). Berlin/New York: Mouton de Gruyter.

Müller, C. (1998a). Redebegleitende Gesten Kulturgeschichte - Theorie - Sprachuergleich. Berlin: Berlin-Verlag.

Müller, C. (1998b). Iconicity and gesture. In S. Santi, I. Guaitella, C. Cavé \& G. Konopczynski. (Eds.), Oralité et Gestualité: Communication Multimodale, Interaction (pp. 321-328). Montréal, Paris: L'Harmattan.

Müller, C. (2003). Gestik als Lebenszeichen "toter Metaphem". Tote, schlafende und wache Metaphem. Zeitschrift für Semiotik, 1-2, 61-72.

Müller, C. (2004). The Palm Up Open Hand. A Case of a Gesture Family?. In C. Müller \& R. Posner (Eds.), The Semantics and Pragmatics of Everyday Gestures. The Berlin conference (pp. 233-56). Berlin: Weidler Buchverlag.

Müller, C. (2007). A dynamic view on gesture, language and thought. In S. D. Duncan, J. Cassell \& E. Levy (Eds.), Gesture and the dynamic dimension of language. Essays in bonor of Darid McNeill (pp. 109-116). Amsterdam/Philadelphia: John Benjamins.

Müller, C. (2008a). Metaphors. Dead and alive, sleeping and waking. A dynamic viess. Chicago: University of Chicago Press.

Müller, C. (2008b). What gestures reveal about the nature of metaphor. In A. Cienki \& C. Müller (Eds.), Metaphor and Gesture (pp. 219-245). Amsterdam/Philadelphia: John Benjamins.

Müller, C. (2010a). Wie Gesten bedeuten. In I. Mittelberg (Ed.), Sprache und Geste. Sprache und Literatur 105 (1), 37-68.

Müller, C. (2010b). Mimesis und Gestik. In G. Koch, C. Voss \& M. Vöhler (Eds.), Die Mimesis und ibre Künste. München: Fink, 149-187.

Müller, C. (in prep.). Meaning construal in gesture. In D. Geerarts \& H.-J. Schmidt (Eds.), Cognitive Pragmatics. Amsterdam: John Benjamins. 
Müller, C. \& Cienki, A. (2009). When speech and gesture come together. Forms of multimodal metaphor in the use of spoken language. In C. Forceville \& E. UriosAparisi (Eds.), Multimodal Metaphor (pp. 299-332). Amsterdam/Philadelphia: John Benjamins.

Oakley, T. (2008). From Attention to Meaning: Explorations in Semiotics, Linguistics, and Rbetoric. Bern, Berlin, Bruxelles, Frankfurt am Main, New York, Oxford, Wien: Peter Lang Publishing Group.

Ozyurek, A. (2002). Do speakers design their co-speech gestures for their addresees? The effects of addressee location on representational gestures. Joumal of Memory and Language, 46 (4), 688-704.

Özyürek, A., Kita, S., Allen, S., Brown, A., Furman, R. \& Ishizuka, T. (2008). Development of cross-linguistic variation in speech and gesture: Motion events in English and Turkish. Developmental Psychology, 44 (4), 1040-1054.

Ozyürek, A., Kita, S., Allen, S., Furman, R \& Brown, A. (2005). How does linguistic framing of events influence co-speech gestures? Insights from crosslinguistic variations and similarities. Gesture, 5 (1), 215-237.

Pragglejaz Group (2007). MIP: A method for identifying metaphorically used words in discourse. Metaphor and Symbol, 22, 1-39.

Sacks, H., Schegloff, E. \& Jefferson, G. (1974). A simplest systematics for the organization of tum-taking for conversation. Language, 50, 696-735.

Sheets-Johnstone, M. (1999). The primagy of movement. Amsterdam: John Benjamins.

Steen, G. J. (2008). The Paradox of Metaphor: Why We Need a Three-Dimensional Model of Metaphor. Metaphor and Symbol, 23 (4), 213-241.

Steen, G. J., Dorst, A. G., Hermann, J. B., Kaal, A. A., Krennmayr, T. \& Pasma, T. (2010). A method for linguistic metaphor identification: From MIP to MIPVU. Amsterdam/Philadelphia: John Benjamins.

Searle, J. (1993). Metaphor. In A. Ortony (Ed.), Metaphor and Thought (pp. 83-111). Cambridge: Cambridge University Press.

Stibbe, A. (1996). Metaphor and alternative conceptions of illness. Unpublished Ph.D. thesis. Lancaster University.

Streeck, J. (1988). The significance of gesture: How it is achieved. Papers in Pragmatics, 2, 60-83.

Streeck, J. (1993). Gesture as Communication 1: Its Coordination with Gaze and Speech. Communication Monographs, 60 (4), 275-299.

Streeck, J. (1996). How to do things with things: Objets trouvés and symbolization. Human Studies, 19, 365-384.

Streeck, J. (2009). Gesturecraft. The manu-facture of meaning. Amsterdam/New York: John Benjamins.

Streeck, J. \& LeBaron, C. (2000). Gestures, knowledge, and the world. In D. McNeill (Ed.), Language and Gesture: Window into Thought and Action (pp. 118-138). Cambridge: Cambridge University Press.

Streeck, J. \& Kallmeyer, W. (2001). Interaction by inscription. Joumal of Pragmatics, 33 (4), 465-490.

Tag, S. (2006). Gestenkomplexe in der Erzäblung 'Der Schulbeutel. Unpublished working paper, Freie Universität Berlin.

Tag, S. (in prep.). Simultaneous constructions in co-speech gestures. In J. Bressem \& S.

H. Ladewig (Eds.), Hand made patterns. Recurrent forms and functions in gestures. 
Talmy, L. (2007). Attention phenomena. In D. Geeraerts \& H. Cuyckens (Eds.), Oxford bandbook of cognitive linguistics (pp. 264-293). Oxford: Oxford University Press.

Willems, R M., Toni, I., Hagoort, P. \& Casasanto, D. (2009). Body-specific motor imagery of hand actions: Neural evidence from right-and left-handers. Frontiers in Human Neuroscience, 3 (39), 1-9. 